\title{
Correlation Between Computerized Tomography Findings and DeMeester Score and Esophagogastroduodenoscopy Findings in Patients with GERD-like Symptoms
}

\section{GERH Benzeri Semptomları Olan Hastalarda Bilgisayarlı Tomografi Bulguları ile DeMeester Skoru ve Özofagogastroduodenoskopi Bulguları Arasındaki İlişki}

\author{
(D) Hakan Yirgin1, (D) İnci Kızıldağ Yirgin², (D) Süleyman Sönmez ${ }^{3}$ \\ ${ }^{1}$ University of Health Sciences Turkey, Kanuni Sultan Süleyman Training and Research Hospital, Clinic of Gastroenterology Surgery, Istanbul, Turkey \\ ${ }^{2}$ Istanbul University Institute of Oncology, Department of Radiology, Istanbul, Turkey \\ 3 University of Health Sciences Turkey, Kanuni Sultan Süleyman Training and Research Hospital, Clinic of Radiology, Istanbul, Turkey
}

\begin{abstract}
Objective: Radiological imaging has a limited role in the initial diagnosis of gastroesophageal reflux disease (GERD) without complications. This study aimed to investigate the correlation with the presence of hiatal hernia $(\mathrm{HH})$, the number of hiatal area pixels, the angle of His on computerized tomography (CT) imaging, esophagogastroduodenoscopy (EGD) findings, and DeMeester scores in patients with GERD-like symptoms.

Methods: This retrospective study included 46 consecutive patients with typical GERD-related symptoms. All patients underwent EGD examinations. Patients were divided into two groups as $\mathrm{HH}$ and hiatal insufficiency based on the EGD results. The DeMeester score of $>14.72$ was considered abnormal acid reflux, whereas $<14.72$ was normal. Anatomical details of esophageal hiatus on CT were separately recorded.

Results: A statistically significant correlation was found between EGD and CT imaging findings using the Pearson correlation test ( $p<0.05$ ). No statistically significant difference was found between the number of hiatal area pixels and DeMeester scores using the Mann-Whitney $U$ test $(p=0.49)$. No statistically significant difference was found between the angle of His and DeMeester scores using the Mann-Whitney $U$ test $(p=0.45)$.
\end{abstract}

Conclusion: Anatomical details of esophageal hiatus are correlated with endoscopy findings in CT imaging.

Keywords: Gastroesophageal reflux, DeMeester score, endoscopy, hiatal hernia, pH-metry, tomography

öz

Amaç: Radyolojik görüntüleme yöntemleri, komplikasyon gelişmemiş gastroözofageal reflü hastalığının (GERH) ilk tanısında sınırlı bir role sahiptir. Bu çalışmada, GERH tanısı bulunan hastalarda hiatal herni $(\mathrm{HH})$ varlığı, hiatal alandaki piksel sayısı, bilgisayarlı tomografi (BT) görüntülemede His açısı, özofagogastroduodenoskopi (EGD) bulguları ve DeMeester skorları arasındaki korelasyonu araştırmayı amaçladık.

Gereç ve Yöntem: Bu retrospektif çalışmaya tipik GERH ile ilgili semptomlarla başvuran 23 ila 74 yaşları arasındaki 46 hasta (medyan yaş 46,24 erkek ve 22 kadın) dahil edildi. Tüm çalışma hastalarına EGD incelemeleri yapıldı. EGD sonuçlarına göre hastalar HH ve hiatal yetmezlik olarak iki gruba ayrıldı. DeMeester skorunun 14.72 'den fazla olması anormal asit reflü, 14.72 'den az olması normal sonuç olarak kabul edildi. BT'de özofagus boşluğunun anatomik detayları ayrı ayrı kaydedildi.

Bulgular: Pearson korelasyon testinde EGD bulguları ile BT görüntüleme bulguları arasında istatistiksel olarak anlamlı bir korelasyon vardı $(p<0,05)$. Mann-Whitney U testinde hiatal alandaki piksel sayısı ile DeMeester skoru arasında istatistiksel olarak anlamlı bir fark saptanmadı $(p=0,49)$. Benzer şekilde, Mann-Whitney $U$ testinde His açısı ve DeMeester skoru arasında istatistiksel olarak anlamlı bir fark bulunmadı $(p=0,45)$.

Sonuç: BT görüntülemede elden edilen özofagial hiatusa ait anatomik detaylar endoskopi bulguları ile korelasyon göstermektedir.

Anahtar Kelimeler: Gastroözofageal reflü, De Meester skoru, endoskopi, hiatal herni, pH-metri, tomografi

Address for Correspondence: İnci Kızıldağ Yirgin, Istanbul University Institute of Oncology, Department of Radiology, Istanbul,

Turkey

Phone: +90 5308204689 E-mail: incikizil@hotmail.com ORCID ID: orcid.org/0000-0003-0563-5964

Cite as: Yirgin H, Kızıldağ Yirgin I, Sönmez S. Correlation Between Computerized Tomography Findings and DeMeester Score and

Esophagogastroduodenoscopy Findings in Patients with GERD-like Symptoms. Med J Bakirkoy 2021;17:327-333

Received: 06.07.2021

Accepted: 19.11.2021 


\section{INTRODUCTION}

Gastroesophageal reflux disease (GERD) is the most common gastrointestinal disease that affects $15-20 \%$ of people in the United States and 5\% in Asia (1). A proper definition of GERD is very important for initiating efficacious therapy and avoiding esophageal problems, such as Barret's esophagus and adenocarcinoma. Cross-sectional imaging has an obvious role in GERD diagnosis and complication evaluation, as well as benign and malign lesion differentiation in staging and post-therapy evaluation of esophageal carcinoma (2). According to the American Gastroenterological Association guideline, esophagogastroduodenoscopy (EGD), of which symptoms do not decrease after proton pump inhibitor (PPI) treatment, is the most prevalent following step for a certain diagnosis and complication evaluation. The second step for patients with a suspected GERD syndrome, who have not responded to an empiric therapy of PPI, have normal results on endoscopy but without significant findings on manometry in $\mathrm{pH}$ monitoring (3).

Radiological imaging has a restricted role in primary GERD diagnosis without complications. Fluoroscopic esophagography has been routinely used by radiologists as a safe, available, and inexpensive method but is not advisable for GERD determination following the revised guidelines $(4,5)$. Studies documented no correlation between barium esophagography with $\mathrm{pH}$ monitoring (6).

In recent years, cross-sectional radiological methods were more frequently used in patients with reflux symptoms to exclude cardiac and pulmonary differential diagnoses. This data accumulation prompted radiologists to radiologically evaluate the esophageal hiatus and gastroesophageal junction and investigate its correlation with symptoms. A few studies showed that dynamic magnetic resonance imaging (MRI) swallowing is an appropriate method to assess patients with gastroesophageal reflux complaints $(7,8)$. One study evaluated the correlation between the distal esophageal wall thickness on computerized tomography (CT) and the presence of reflux esophagitis (RE), which found a moderate association (9). The importance of accurate measurements of esophageal hiatus in the preoperative period was noticed with increased anti-reflux surgeries. CT measurement of hiatal surface area has the potential to preoperatively guide decision-making in anti-reflux surgery technique, and the same methodology can be used to post-operatively assess surgical results. Yildirim et al. (10) measured the abdominal part of esophageal length (IAEL) and cardio-esophageal angle (COA) to identify patients with GERD in 2011. They revealed that the $C T$ imaging method could be used for IAEL and COA measurements with a good degree of disease concordance (10). Koch et al. (11) published a study in 2012, wherein they investigated the association between the hiatal hernia $(\mathrm{HH})$ size that was preoperatively measured and the esophageal hiatus size that was intraoperatively measured using the barium swallow imaging method. This study demonstrated a poor sensitivity of preoperative barium swallow examination, and surgeons could not rely on these imaging method findings (11). Ouyang et al. (12) published a study in 2016, wherein they measured the hiatal surface area on CT and showed evidence of hiatal $\mathrm{HH}$ associated with wide hiatuses and GERD. Additionally, their work revealed an inadequate hiatal surface area to determine GERD without CT findings (12).

To our knowledge, the correlation between DeMeester score and CT imaging measurement findings in patients with GERD-like symptoms has not been published. This study focused to research the correlation with the $\mathrm{HH}$ presence, the number of hiatal area pixels, the angle of His on $C T$ imaging and EGD findings, and DeMeester scores in patients with GERD-like symptoms.

\section{METHODS}

\section{Participants}

This retrospective study included 46 consecutive patients aged 23 to 74 years (median age 46 years, 24 males and 22 females) who presented themselves in our surgical outpatient clinic with typical GERD-related symptoms. The hospital archive was searched between March 2019 and March 2020, which showed that 60 patients had CT scan, $E G D$, and $24 \mathrm{~h}$ esophageal $\mathrm{pH}$-metry in less or equal to six months apart. Excluded from the study were 14 patients with inadequate clinical information or non-diagnostic CT scans. None of the patients were diagnosed with achalasia or scleroderma and none had prior gastrointestinal surgery. All patients had permanent or repetitive GERD symptoms despite therapy with PPI in at least 6 months. This study was approved by the Ethics Committee of University of Health Sciences Turkey, Kanuni Sultan Süleyman Training and Research Hospital (no: 15916306-604.01.01). All patients signed written informed consent before every medical examination.

\section{Esophagogastroduodenoscopy}

All study participants underwent upper gastrointestinal endoscopic examinations. Patients were classified into two groups as $\mathrm{HH}$ and hiatal insufficiency following the EGD results. The diagnostic criterion of endoscopic $\mathrm{HH}$ was accepted as the proximal dislocation of the gastroesophageal junction of $>2 \mathrm{~cm}$ above the 
diaphragmatic indentation. Hiatal insufficiency was defined when gastroesophageal junction at the normal location but presented with respiration-dependent incomplete closure of the cardi around the endoscope. Standard upper gastrointestinal endoscopy using the Fujinon (Fujifilm, light source XL-4450) video gastroduodenoscopies was done to determine the presence of macroscopic causes.

\section{pH-metry/DeMeester Score}

A 24-hour esophageal $\mathrm{pH}$ monitoring was applied with a catheter passing through the nasal cavity and located in the distal esophagus. $\mathrm{A} \mathrm{pH}$ sensor of $>5 \mathrm{~cm}$ from the level of the lower esophageal sphincter was fixed with the catheter and attached to a movable recorder tool for $24 \mathrm{~h}$. After catheter placement, patients went to their homes and suggested doing normal routine jobs. The conventional DeMeester score was evaluated by a medical measurement system (MMS, UPS 2020, ORION II). DeMeester score includes these following parameters: the number of reflux events, the total duration of $\mathrm{pH}$ of $<4(\%)$, duration of $\mathrm{pH}$ of $<4$ in vertical and horizontal positions (\%), the number of reflux events $>5 \mathrm{~min}$, and the period of the major reflux event (13). A result of $>14.72$ was decided as acid reflux, whereas $<14.72$ was normal.

\section{Imaging Analysis}

CT images that are obtained based on different clinical symptoms, at most 6 months before EGD, were included in the study. All scans were obtained with a 16-slice CT scanner (Siemens Somatom Emotion, Siemens Medical Systems, Erlangen, Germany). Examinations that excluded the esophageal hiatus in the imaging area were excluded from the study. Non-contrast abdominal CT imaging for urinary symptoms was determined in 15 patients, whereas 8 had intravenous (IV) contrast-enhanced thorax CT imaging for pulmonary symptoms, and 23 had both IV and oral contrast-enhanced abdominal CT imaging due to upper abdominal pain. Before oral contrast examination, $1.5 \mathrm{I}$ of diluted oral contrast material $(76 \%, 50 \mathrm{~mL}$ of diatrizoic acid, Bayer-Schering Pharma, Seoul, Korea) was administered. IV injection of nonionic iodinated contrast (iohexol of 300 mg; Amersham Health, Cork, Ireland) was applied at a dosage of $1 \mathrm{~mL} / \mathrm{kg}$. Two radiologists with experience in abdominal radiology ( 6 and 4 years, respectively) evaluated the CT sections and did calculations. Esophagogastric junction localization was defined by esophageal tubular contour and angle of His changes. All CT scans were assessed for $\mathrm{HH}$ without quantitative definition with these parameters. Measurements were made using sagittal reformatted CT sections of the esophageal hiatus. A grading system devised by Ouyang et al. (12) was used to categorize patients as possible, probable, or definite $\mathrm{HH}$. Our study used the same grading system and $\mathrm{HH}$ was considered present if the length of the hernia was $>2 \mathrm{~cm}$ from the esophageal hiatus plane. Length between 1 and $2 \mathrm{~cm}$ was determined as probable $\mathrm{HH}$ and length between 0 and $1 \mathrm{~cm}$ was determined as possible HH (Figure 1). The number of hiatal area pixels was measured on axial CT sections using ImageJ software (National Institutes of Health, USA). ImageJ version 1.46 is a free accessible software program that was created by the National Institutes of Health for image postprocessing and evaluation (downloadable from http://rsbweb.nih.gov/ ij/download.html). The hiatal areas were manually drawn. The number of pixels in the drawn areas was calculated with this program (Figure 2). The angle of His was measured on coronal CT reformatted images by two lines formed to the right wall of the gastric fornix and abdominal esophageal wall (Figure 1).

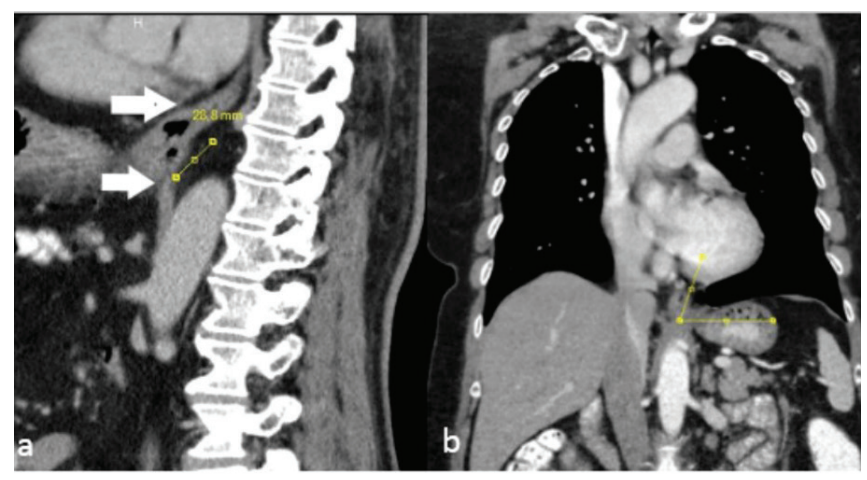

Figure 1. a) Sagittal CT sections of the esophageal hiatus shows definite $\mathrm{HH}$, Length of the hernia at $2 \mathrm{~cm}$ above (superior arrow) the level of the esophageal hiatus (inferior arrow). b) Coronal CT images of the esophageal hiatus shows the angle of His that formed by the abdominal esophageal wall and the right wall of the gastric fornix CT: Computerized tomography, $\mathrm{HH}$ : Hiatal hernia

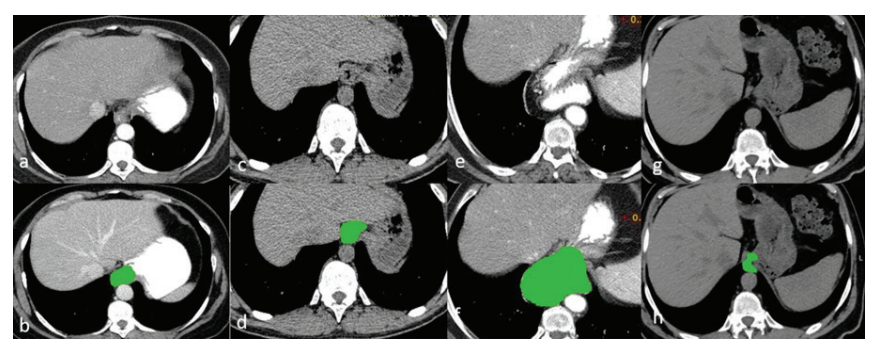

Figure 2. a,b) a 60-year-old female patient presented with axial CT images passing through the level of the esophageal hiatus. The number of pixels in the green area was calculated as 937. c,d) a 28-year-old male patient presented with axial CT images passing through the level of the esophageal hiatus. The number of pixels in the green area is calculated as 903. e,f) a 63-year-old female patient presented with axial CT images passing through the level of the esophageal hiatus. The number of pixels in the green area was calculated as 5195. g,h) a 59-year-old male patient presented with axial CT images passing through the level of the esophageal hiatus. The number of pixels in the green area was calculated as 640 CT: Computerized tomography 


\section{Statistical Analysis}

The analysis was performed using the Statistical Package for the Social Sciences International Business Machines version 20 (SPSS Inc., Chicago, IL, USA). The relationship between variables was evaluated using the Pearson correlation, and independent groups were investigated by the Chi-square and Mann-Whitney $U$ tests. The receiver operating characteristic curve was created to quantitatively measure data, and cut-off values were calculated according to sensitivity and specificity values. P-values of $<0.05$ were considered statistically significant.

\section{RESULTS}

\section{Participants}

This study included 24 male and 22 female patients with a mean age of 46 years (range, 23-74).

\section{Correlation Between EGD and CT Imaging}

Participants were classified into two groups based on EGD results as $\mathrm{HH}$ and hiatal insufficiency. The hiatal insufficiency group included 26 patients, whereas 20 in the $\mathrm{HH}$ group. The CT images evaluation determined 4 patients in the possible hernia group, 19 in the probable hernia group, and 23 in the definite hernia group (Table 1). A statistically significant correlation was found between the groups using the Pearson correlation test $(p<0.05)$. The Chi-square tests were used to evaluate the difference between the groups, which revealed a statistically significant difference $(p=0.001)$.

\section{DeMeester Score and CT Measurements}

DeMeester scores of 14 patients were $<14.72$, whereas scores of 32 patients were $>14.72$. The CT images evaluation determined 4 patients in the possible hernia group, 19 in the

Table 1. Evaluation of EGD and CT results

\begin{tabular}{lllll} 
EGD & Possible & Probable & Definite & Total \\
\hline Hiatal insufficiency & 4 & 15 & 7 & 26 \\
\hline Hiatal hernia & 0 & 4 & 16 & 20 \\
\hline Total & 4 & 19 & 23 & 46 \\
\hline
\end{tabular}

EGD: Esophagogastroduodenoscopy, CT: Computerized tomography

Table 2. Evaluation of DeMeester score and number of pixels and angel of His

\begin{tabular}{lll} 
DeMeester score & $\begin{array}{l}\text { Number of } \\
\text { pixels (mean) }\end{array}$ & $\begin{array}{l}\text { Angel of His } \\
\text { (mean) }\end{array}$ \\
\hline$<14.7$ & 636 & $90.8^{\circ}$ \\
\hline$>14.7$ & 1085 & $94.2^{\circ}$ \\
\hline$p$ & 0.49 & 0.45 \\
\hline
\end{tabular}

probable hernia group, and 23 in the definite hernia group. The Chi-square test was used to analyze the differences between groups, which revealed no statistically significant difference $(p=0.17)$. No statistically significant difference was observed between the number of hiatal area pixels and DeMeester scores using the Mann-Whitney $U$ test $(p=0.49)$ (Table 2). When the cut-off value for the number of hiatal area pixels was set as 600 , the sensitivity and specificity of CT imaging for correlation with DeMeester score were $50 \%$ and $48 \%$, respectively (Figure 3). CT imaging of 5 patients was unable to measure the angle of His because of severe sliding $\mathrm{HH}$. The mean degree of angle was $90.8^{\circ}$ in patients who had $<14.7$ DeMeester scores, whereas $94.2^{\circ}$ in patients who had $>14.7$ DeMeester scores. No statistically significant difference was found between the angle of His and DeMeester scores using the Mann-Whitney $U$ test $(p=0.45)$. The sensitivity and specificity of CT imaging for the DeMeester score were $48 \%$ and $50 \%$, respectively when the cut-off value for the angle of His was set as $92.1^{\circ}$ (Figure 3).

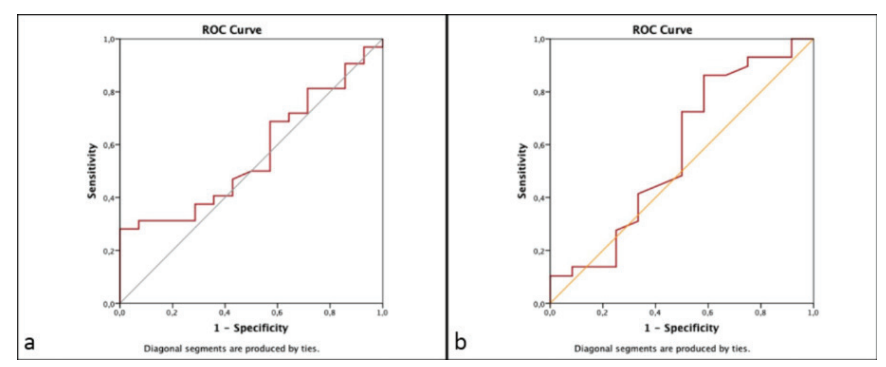

Figure 3. a) Receiver operating characteristic analysis of the number of hiatal area pixels for correlation with DeMeester score. b) Receiver operating characteristic analysis of the angle of His for correlation with DeMeester score

ROC: Receiver operating characteristic

\section{DISCUSSION}

Anatomical changes of the esophageal hiatus are important for surgeons before anti-reflux or HH surgery (14). The surgeon's decision about hernia repair method depends on HH size (15). EGD provides diagnosis and description of mucosal abnormalities that are associated with reflux and $\mathrm{HH}$ or reflux complications. $\mathrm{PH}$-metry is used to show the presence of reflux in cases with positive EGD results in the preoperative management. This study evaluated the CT imaging measurements of the esophageal hiatus and EGD results with DeMeester scores in patients with GERD-like symptoms to show the effectiveness of CT imaging as a replacement of $\mathrm{pH}$-metry, an uncomfortable method in the esophagus for 24 hours. 
First, our study provides $\mathrm{CT}$ imaging to assess $\mathrm{HH}$ in patients with GERD-like symptoms. CT imaging shows a well diagnostic capacity for $\mathrm{HH}$ diagnosis compared with EGD results. None of the patients with EGD result in the $\mathrm{HH}$ group was included in the possible group (hernia length 0-1 cm) in CT examination, whereas 16 patients were included in the definite group (hernia length $>2 \mathrm{~cm}$ ) and 4 in the probable group (hernia length 1-2 cm). Radiological methods and $\mathrm{HH}$ presence is an old area of research. Koch et al. (11) investigated the association between $\mathrm{HH}$ size that was measured in the preoperative period and the esophageal hiatus size in the intraoperative period. They used barium swallow examination and demonstrated no correlation between the preoperative and postoperative measurements $(p=0.073)$. CT examination was more successful in anatomical details, thus studies were started to publish with this imaging method. Revelli et al. (16) published a study in 2015, which revealed that it is not necessary to report minimally sliding $\mathrm{HH}$ when reporting $\mathrm{CT}$ with water enema and CT colonography examinations especially in patients with non-GERD-related symptoms. All patients in our study had GERD-related symptoms. Unlike our study, a healthy control group was included in their study and CT techniques were performed by increasing the intestinal content and abdominal distention. They emphasized that the patient's anamnesis and symptoms were very important in evaluating CT sections. Another study by Ouyang et al. (12) revealed the presence of $\mathrm{HH}$ that correlated with large hiatus and GERD with multiplanar CT imaging. Additionally, the presence of $\mathrm{HH}$ was not correlated with endoscopic findings, as in our study. One study showed that endoscopic gastroesophageal flap valve (GEFV) grade has a good correlation with $\mathrm{HH}$ presence in CT imaging (17).

Second, correlations between DeMeester score and anatomical CT measurements of the esophageal hiatus were not statistically significant. Possible, probable, and definite $\mathrm{HH}$ groups had no statistically significant score differences. However, the study published by Ouyang et al. (12) revealed that patients with $\mathrm{HH}$ had more GERD. This difference may be related to the method used to detect GERD. They considered as positive those patients who had heartburn and typically used medication to treat GERD. All patients had heartburn and were treated with typical medication for 6 months. PH-metry was used, which is accepted as the gold standard for GERD diagnosis $(18,19)$. Secondly, the number of participants who had a DeMeester score of $<4.7$ was only 14 , whereas 32 in the DeMeester score of $>14.7$. A feasibility study researched the efficacy of 320-row area detector CT to assess morphological abnormalities of the esophageal hiatus (20). Their study participants were volunteers in good health and patients diagnosed with esophagitis caused by reflux. They found more occurrence of $\mathrm{HH}$ in patients with severe $\mathrm{RE}$, which is explained by the dynamic-like technique in CT examination (non-swallowing and swallowing phases) and different patient profiles. Another parameter that was measured as the number of hiatal area pixels. Similarly, we found no statistically significant differences between the two groups according to the DeMeester score. Additionally, low sensitivity and specificity (50\% and $48 \%$, respectively) values were obtained with a cut-off value of 600 for the number of pixels. Many studies investigated the hiatal area in the literature, but none directly investigated the DeMeester score and the number of hiatal area pixels $(12,17,20)$. The study published by Ouyang et al. (12) showed that patients with GERD had larger hiatuses than the normal (healthy volunteers) group. As previously mentioned, this difference may be related to the method used to detect GERD. However, their measurement technique was not significantly different from ours. They made CT postprocessing in a double-oblique plane to demonstrate the hiatal area and manually trace the hiatus then calculate this area in $\mathrm{mm}^{2}$. We checked the sagittal and coronal reformatted planes before measurement and manually traced the correct section and calculated the number of hiatal area pixels. The study results published by Jeon et al. (17) revealed abnormal GEFV associated with larger diaphragmatic hiatus. Unlike our study, they compared the GEFV to the hiatal area, whereas we compared the presence of reflux and the hiatal area. Fukazawa et al. (20) showed that patients with RE showed larger hiatal area and greater His angle than healthy volunteers. They measured the horizontal size of the diaphragmatic hiatus in $\mathrm{mm}^{2}$. We found no statistically significant differences between the angle of His and two groups according to the DeMeester score. Additionally, very low sensitivity and specificity (50\% and $48 \%$, respectively) values were obtained with a cut-off degree of $92.1^{\circ}$. Yildirim et al. (10) found the sensitivity and specificity of ultrasound for reflux diagnosis as $76 \%$ and $72 \%$, respectively, when the cut-off value of the angle of His was set as $138.5^{\circ}$. The same study revealed the sensitivity and specificity values as $83 \%$ and $80 \%$, respectively, for CT imaging with the same cut-off value (10). This difference in the literature is due to the angle of His variability due to dynamic anatomy. The angle of sensation may differ during and after swallowing or inspiration and expiration. Therefore, dynamic and realtime imaging has been investigated. In 2010 Curcic et al. (21) showed that MRI has a great agreement in reflux diagnosis with the high-resolution manometry as a reference standard.

A recently published study by Seif Amir Hosseini et al. (22) evaluated 91 patients with GERD-like symptoms. Reflux was 
detected in 60 of 91 patients (66\%) by real-time MRI. The $\mathrm{pH}$-metry results revealed reflux in 41 of 91 patients (45\%). Additionally, reflux was detected by impedance in 54 of 91 patients (59\%). Compared to $\mathrm{pH}$-metry and impedance, real-time MRI sensitivity, specificity, and PPV were 0.78 , 0.67 , and 0.87 , respectively. Real-time MRI was observed as a favorable useful diagnostic method for GERD due to its relation with $\mathrm{pH}$-metry and impedance results and its high positive predictive value. It is a non-invasive method, thus it can be used before other invasive methods.

\section{Study Limitations}

Our study had some limitations. First, a small number of patients was included and the method is retrospective. DeMeester score and CT imaging measurement findings were compared in patients with GERD-like symptoms. DeMeester's score is based on acidic reflux; however, basic reflux can also cause symptoms in patients.

\section{CONCLUSION}

The relationship between anatomical data obtained from $\mathrm{CT}$ imaging and $\mathrm{pH}$-metry is unclear due to differently designed studies in the literature. However, anatomical details of esophageal hiatus are correlated with endoscopy findings in CT imaging. MR examination should be used in future studies due to its dynamic and real-time sequences.

\section{ACKNOWLEDGMENTS}

The authors would like to express their gratitude to all patients who participated in this study.

\section{ETHICS}

Ethics Committee Approval: This study was approved by the Ethics Committee of University of Health Sciences Turkey, Kanuni Sultan Süleyman Training and Research Hospital (no: 15916306-604.01.01).

Informed Consent: All patients signed written informed consent before every medical examination.

\section{Authorship Contributions}

Surgical and Medical Practices: H.Y., S.S., Concept: I.K.Y., Design: H.Y., I.K.Y., S.S., Data Collection or Processing: H.Y., I.K.Y., S.S., Analysis or Interpretation: H.Y., I.K.Y., S.S., Literature Search: H.Y., S.S., Writing: I.K.Y.

Conflict of Interest: No conflict of interest was declared by the authors.

Financial Disclosure: The authors declared that this study received no financial support.

\section{REFERENCES}

1. Dent J, El-Serag HB, Wallander MA, Johansson S. Epidemiology of gastro-oesophageal reflux disease: a systematic review. Gut 2005;54:710-7.

2. Manning MA, Shafa S, Mehrotra AK, Grenier RE, Levy AD. Role of Multimodality Imaging in Gastroesophageal Reflux Disease and Its Complications, with Clinical and Pathologic Correlation. Radiographics 2020:40:44-71.

3. Kahrilas PJ, Shaheen NJ, Vaezi MF, Hiltz SW, Black E, Modlin IM, et al. American Gastroenterological Association Medical Position Statement on the Management of Gastroesophageal Reflux Disease. Gastroenterology 2008;135:1383-91.

4. Johnston BT, Troshinsky MB, Castell JA, Castell DO. Comparison of barium radiology with esophageal $\mathrm{pH}$ monitoring in the diagnosis of gastroesophageal reflux disease. Am J Gastroenterol 1996;91:1181-5.

5. Gyawali CP, Kahrilas PJ, Savarino E, Zerbib F, Mion F, Smout AJPM, et al. Modern diagnosis of GERD: the Lyon Consensus. Gut 2018;67:1351-62.

6. Saleh CM, Smout AJ, Bredenoord AJ. The diagnosis of gastroesophageal reflux disease cannot be made with barium esophagograms. Neurogastroenterol Motil 2015;27:195-200.

7. Kulinna-Cosentini C, Schima W, Cosentini EP. Dynamic MR imaging of the gastroesophageal junction in healthy volunteers during bolus passage. J Magn Reson Imaging 2007;25:749-54.

8. Seif Amir Hosseini A, Beham A, Uhlig J, Streit U, Uhlig A, Ellenrieder $V$, et al. Intra- and interobserver variability in the diagnosis of GERD by real-time MRI. Eur J Radiol 2018;104:14-9.

9. Lambert L, Grusova G, Burgetova A, Matras P, Lambertova A, Kuchynka $P$. The predictive value of computed tomography in the detection of reflflux esophagitis in patients undergoing upper endoscopy. Clin Imaging 2018;49:97-100.

10. Yildirim D, Ekçi B, Gürses B, Oruç F. Evaluation of the gastrooesophageal junction: defining the incompetent cardiooeosophageal angle non-invasively with ultrasound and computerized tomography. J Int Med Res 2011;39:1193-200.

11. Koch OO, Schurich M, Antoniou SA, Spaun G, Kaindlstorfer A, Pointner $\mathrm{R}$, et al. Predictability of hiatal hernia/defect size:is there a correlation between pre- and intraoperative findings? Hernia 2014;18:883-8.

12. Ouyang W, Dass C, Zhao H, Kim C, Criner G; COPDGene Investigators. Multiplanar MDCT measurement of esophageal hiatus surface area: association with hiatal hernia and GERD. Surg Endosc 2016;30:2465-72.

13. DeMeester TR, Wang Cl, Wernly JA, Pellegrini CA, Little AG, Klementschitsch $\mathrm{P}$, et al. Technique, indications, and clinical use of 24-hour esophageal $\mathrm{pH}$ monitoring. J Thorac Cardiovasc Surg 1980;79:656-70.

14. Kahrilas PJ, Kim HC, Pandolfino JE. Approaches to the diagnosis and grading of hiatal hernia. Best Pract Res Clin Gastroenterol 2008;22:601-16.

15. Grubnik W, Malynovskyy AV. Laparoscopic repair of hiatal hernias: new classification supported by long-term results. Surg Endosc 2013;27:4337-46.

16. Revelli M, Furnari M, Bacigalupo L, Paparo F, Astengo D, Savarino $E$, et al. Incidental physiological sliding hiatal hernia: a single center comparison study between CT with water enema and CT colonography. Radiol Med 2015;120:683-9.

17. Jeon HK, Kim GH, Lee NK, Kim S, Lee BE, Song GA. Analysis of computed tomographic findings according to gastroesophageal flap valve grade. Korean J Intern Med 2018;33:295-303. 
18. Fink SM, McCallum RW. The Role of Prolonged Esophageal pH Monitoring in the Diagnosis of Gastroesophageal Reflux. JAMA 1984;252:1160-4.

19. DeMeester T, Wang C-I, Johnson L, Skinner D. Comparison of Clinical-Test for Detection of Gastroesophageal Reflux. Basel, Switzerland: Karger Allschwilerstrasse 10, Ch-4009;1979.

20. Fukazawa K, Furuta K, Adachi K, Shimura S, Kamiyama K, Aimi M, et al. Continuous imaging of esophagogastric junction in patients with reflux esophagitis using 320-row area detector CT: a feasibility study. J Gastroenterol Hepatol 2013;28:1600-7.
21. Curcic J, Fox M, Kaufman E, Forras-Kaufman Z, Hebbard GS, Roy $S$, et al. Gastroesophageal junction: structure and function as assessed by using MR imaging. Radiology 2010;257:115-24.

22. Seif Amir Hosseini A, Uhlig J, Streit U, Gliem N, Wedi E, Ellenrieder $V$, et al. Real-time MRI for dynamic assessment of gastroesophageal reflux disease: Comparison to $\mathrm{pH}$-metry and impedance. Eur $\mathrm{J}$ Radiol 2020;125:108856. 